\title{
Encefalite viral como complicação de dengue no oeste paranaense
}

\author{
Viral encephalitis as a complication of dengue in western Paraná \\ Encefalitis viral como complicación del dengue en el oeste de Paraná
}

Recebido: 20/07/2021 | Revisado: 26/07/2021 | Aceito: 30/07/2021 | Publicado: 05/08/2021

\author{
Wesley Gabriel Novaes Botelho \\ ORCID: https://orcid.org/0000-0001-7315-4201 \\ Universidade Federal do Paraná, Brasil \\ E-mail: wesleygabriel_dte@hotmail.com \\ Anderson Dillmann Groto \\ ORCID: https://orcid.org/0000-0002-9028-4371 \\ Universidade Federal do Paraná, Brasil \\ E-mail: andersongr01@gmail.com \\ Beatriz Paiola Albrecht \\ ORCID: https://orcid.org/0000-0002-9989-618X \\ Universidade Federal do Paraná, Brasil \\ E-mail: bialbrecht@hotmail.com \\ Breno Emanuel Santana Rego \\ ORCID: https://orcid.org/0000-0001-6797-9709 \\ Universidade Federal do Paraná, Brasil \\ E-mail: brsantana96@gmail.com \\ Alcântara Ramos de Assis César \\ ORCID: https://orcid.org/0000-0002-7390-7282 \\ Universidade Federal do Paraná, Brasil \\ E-mail: alcantara.cesar@ufpr.br
}

\begin{abstract}
Resumo
A dengue atingiu mais de 770 mil pessoas no Brasil durante os primeiros cinco meses de 2020. Possuindo quatro sorotipos diferentes, é considerada uma infecção viral endêmica grave influenciada pelo nível de urbanização. A confirmação diagnóstica é realizada apenas com o exame sorológico IgM e IgG, mas devido à positivação tardia destes testes, seis e nove dias respectivamente, o tratamento quase sempre é empírico. Entre 1-5\% dos casos de dengue evoluem para doenças neurológicas, tanto pela atuação direta do vírus no sistema nervoso, quanto pela reação imunológica, que acaba manifestando-se de forma mais tardia na forma de encefalite. Este estudo relata o caso de uma paciente com encefalite pós-dengue. Inicialmente a paciente AST, 66 anos, procurou atendimento com queixa de lipotimia e teve alta hospitalar após medidas de suporte. Evoluiu com piora progressiva, apresentando sintomas dispépticos, mialgia e flutuação do nível de consciência, sendo novamente internada para tratamento. Após avaliação multidimensional foi realizada tomografia computadorizada, que não demonstrou alterações e punção liquórica. Foi realizado terapêutica empírica com Valproato de Sódio, Dexametasona, Ceftriaxona, Panciclovir e tratamento de suporte com controle hemodinâmico e das crises convulsivas. Com sorologia IgG dengue positiva a equipe manteve a terapêutica para encefalite viral. A evolução foi favorável com sequelas mínimas, como leve fraqueza proximal e amnésia lacunar. Portanto, conclui-se que infecções pelo vírus da dengue, assim como por outros arbovírus podem causar complicações potencialmente fatais como encefalite viral, necessitando de diagnóstico e intervenção precoce.
\end{abstract}

Palavras-chave: Dengue; Encefalite; Dengue grave; Encefalite viral; Encefalite por arbovírus.

\begin{abstract}
Dengue affected more than 770,000 people in Brazil during the first five months of 2020. Having four different serotypes, it is considered a severe endemic viral infection influenced by urbanization level. Diagnostic confirmation is performed only with the serological IgM and IgG tests, but due to late positivity of these tests, six and nine days respectively, the treatment is almost always empirical. Between 1-5\% of dengue cases evolve into neurological disease, both by the immunological reaction, which ends up manifesting itself later in the form of encephalitis. This study reports the case of a patient with post-dengue encephalitis. Initially, the patient AST, 66 years old, sought care complaining of lipothymia and was discharged from hospital after supportive measures. She evolved with dyspeptic symptoms, myalgia and fluctuating level of consciousness, being hospitalized again for treatment. After multidimensional evaluation, computed tomography was performed, which showed no changes. A CSF puncture was also requested. Empirical therapy was performed with Sodium Valproate, Dexamethasone, Ceftriaxone, Panciclovir and supportive treatment for hemodynamic and seizure control. With positive dengue IgG serology, the team maintained therapy for viral encephalitis. The evolution was favorable with minimal sequelae, such as mild proximal weakness and lacunar amnesia. Therefore, it is concluded that infections by dengue virus, as well as by other arboviruses, can cause potentially fatal complications such as viral encephalitis, requiring early diagnosis and intervention.
\end{abstract}


Keywords: Dengue; Encephalitis; Severe dengue; Viral Encephalitis; Arbovirus Encephalitis.

\section{Resumen}

El dengue afectó a más de 770 mil personas en Brasil durante los primeros cinco meses de 2020. Con cuatro serotipos diferentes, se considera una infección viral endémica severa influenciada por el nivel de urbanización. La confirmación diagnóstica se realiza únicamente con las pruebas serológicas IgM e IgG, pero debido a la positividad tardía de estas pruebas, seis y nueve días respectivamente, el tratamiento casi siempre es empírico. Entre 1-5\% de los casos de dengue evolucionan a enfermedades neurológicas, tanto por la acción directa del virus en el sistema nervioso, como por la reacción inmunológica, que acaba manifestándose posteriormente en forma de encefalitis. Este estudio reporta el caso de un paciente con encefalitis posdengue. Inicialmente, el paciente AST, de 66 años, acude a consulta por lipotimia y es dado de alta hospitalaria tras medidas de soporte. Progresó con empeoramiento progresivo, con síntomas dispépticos, mialgias y fluctuación del nivel del nivel de conciencia, siendo nuevamente hospitalizada para tratamiento. Después de la evaluación multidimensional, se realizó tomografía computarizada, que no mostró alteraciones y punción de LCR. Se realizó terapia empírica con Valproato de Sodio, Dexametasona, Ceftriaxona, Panciclovir y tratamiento de apoyo con control hemodinámico y convulsiones. Con serología IgG de dengue positiva, el equipo mantuvo la terapia para la encefalitis viral. La evolución fue favorable con mínimas secuelas, como leve debilidad proximal y amnesia lacunar. Por tanto, se concluye que las infecciones por el virus del dengue, así como por otros arbovirus, pueden ocasionar complicaciones potencialmente fatales como la encefalitis viral, requiriendo un diagnóstico e intervención precoces.

Palabras clave: Encefalitis; Dengue severo; Encefalitis viral; Encefalitis por arbovirus.

\section{Introdução}

A dengue atingiu mais de 770 mil pessoas no Brasil durante os primeiros cinco meses de 2020 (Ministério da Saúde, 2020). É considerada uma infecção viral endêmica grave influenciada pelo nível de urbanização e onerada pelo clima tropical que favorece o criadouro do maior vetor epidemiológico, mosquitos do gênero Aedes (Khetarpal \& Khanna, 2016; Kamal et al, 2018; Guzman et al, 2016)

De acordo com o Instituto René Rachou (2020), vinculado a Fiocruz, o vírus da dengue possui quatro sorotipos diferentes, DENV-1, DENV-2, DENV-3 e DENV-4, permitindo que uma pessoa infectada no passado possa sofrer uma nova infecção, visto que os anticorpos gerados na doença prévia são atuantes apenas para o sorotipo adquirido, não combatendo os demais três tipos.

A suspeição de dengue é baseada nas manifestações clínicas do paciente, presença de febre, normalmente maior que $38^{\circ} \mathrm{C}$, acompanhada de pelos menos dois dos seguintes sintomas: cefaleia, dor retro-orbitária, mialgia, artralgia, prostração, exantema, náuseas ou vômitos, associado a uma área com presença epidemiológica da doença ou histórico de viagem nos últimos 14 dias para uma área endêmica. A duração média dos sintomas é de sete a dez dias na maioria dos indivíduos (Fonseca, 2016). Segundo o ministério da saúde, a classificação de caso se divide em caso suspeito, casos suspeitos com sinais de alarme, caso suspeito de dengue grave, caso confirmado e caso descartado (Brasil, 2013).

A confirmação diagnóstica é realizada com exames laboratoriais. A sorologia é realizada através do método EnzymeLinked Immunosorbent Assay (ELISA), detectando IgM e IgG, devendo ser realizado após o sexto dia de manifestação clínica (Fonseca, 2016). É possível também realizar a procura direta do vírus ou antígenos virais através das técnicas de RT-PCR, isolamento viral, NS1 e imuno-histoquímica, devendo ser realizado até o quinto dia de sintoma (Brasil, 2013).

No entanto, não existe tratamento específico para o vírus da dengue, é realizada apenas administração medicamentosa para alívio sintomático. Entre 1-5\% dos casos de dengue provocados pelos sorotipos DENV-2 e DENV-3 evoluem para doenças neurológicas, tanto pela atuação direta do vírus no sistema nervoso, gerando inflamação (mielite), quanto pela reação imunológica, que acaba manifestando-se de forma mais tardia, cerca de um mês após o quadro viral clássico (Homero, 2010).

Homero (2010) relata que casos de encefalite são marcados pela repentina redução do nível de consciência, sonolência, convulsões e déficit neurológico focal (perda de força em um dos membros), podendo evoluir para irresponsividade ao meio ambiente e tendo ainda como maior risco a deficiência respiratória. 
A encefalopatia geralmente ocorre secundariamente a disfunção de vários sistemas, como no choque, hepatite e síndrome respiratória aguda. A encefalite como resultado de dengue é rara e poucos casos foram reportados (Baheti et al, 2018; Porwal \& Chauhan, 2016; Varatharaj, 2010).

Outras formas de encefalites, como as autoimunes são mais documentadas na literatura. Embora a apresentação clínica seja diversa e idade de incidência variada, vários anticorpos são direcionados a receptores, como o NMDA, AMPA, GABA (subunidade a e b) e glicina (Newman et al, 2016; Collao-Parra, Urra \& Derio, 2018).

\section{Metodologia}

Trata-se de um estudo de caso descritivo de caráter qualitativo realizado em um hospital público do oeste do Paraná. As informações foram obtidas por meio de entrevista aos familiares, além de revisão dos prontuários médicos da paciente. Após coleta das informações do caso, foram obtidos em artigos científicos e livros especializados dados para realizar a discussão. Como base metodológica utilizou-se o trabalho de Yin (2015).

\section{Resultados}

Paciente A.S.T. 66 anos, sexo feminino, casada, residente em um município do oeste paranaense, procurou o pronto socorro (PS) no dia dez de março de 2020, devido à um "mal-estar" associado a êmese. Foi submetido a tratamento sintomático e a paciente ficou em observação durante o período noturno, tendo alta após melhora parcial dos sintomas.

Nos dias posteriores os sintomas persistiram e no dia vinte de março de 2020 ela retornou ao PS com fadiga, mialgias, dores articulares difusas, náuseas e vômitos. Foram solicitados hemograma (resultados na Tabela 1) e sorologia qualitativa do antígeno NS1. Esta apresentou-se negativa, contudo, o exame NS1 exige uma janela de 1 a 5 dias após a infecção para ser detectado e a paciente foi encaminhada para residência.

Dois dias após a busca do PS, a paciente se dirige ao hospital com piora da êmese e mialgia decorrendo o internamento. Os resultados dos exames laboratoriais desta data estão registrados na Tabela 1. Foram prescritas medidas de suporte e hidratação venosa. Verificou-se melhora sintomática e a paciente seguiu lúcida e orientada, mas relatando ansiedade, sudorese, desconforto epigástrico, mialgia e cefaleia.

O exame físico na admissão hospitalar era o seguinte:

- Frequência Cardíaca: 64 batimentos por minuto (bpm)

- Saturação de $\mathrm{O}_{2}: 96 \%$

- Frequência respiratória: 16 incursões respiratórias por minuto (irpm)

- Pressão Arterial: $140 \times 80 \mathrm{mmHg}$

- Temperatura Axilar: $36,5^{\circ} \mathrm{C}$

- Reflexo fotomotor direto e consensual lentificado à direita.

- Ausculta cardíaca: Bulhas rítmicas normofonéticas em 2 tempos, sem sopros.

- Ausculta pulmonar: Murmúrios vesiculares presentes e distribuídos universalmente.

- Abdome: Ruídos Hidroaéreos presentes, espaço de Traube timpânico, sem defesa ou massas.

- Membros Superiores: Amplitude de movimento direito preservado e flexão à esquerda.

- Membros Inferiores: edema +/++++, pulsos presentes e simétricos.

- Reflexo de Babinski positivo à direita. 
No primeiro dia após internação a paciente apresenta uma queda no estado geral, com um aumento das náuseas, tontura e hiporexia. Com a evolução clínica desfavorável e a suspeição de um quadro sugestivo de patologia gastrointestinal foram solicitados exames laboratoriais (função renal e hepática, Tabela 1) e uma endoscopia, realizada no dia 24 de março, demonstrando uma gastrite erosiva de antro e piloro.

A paciente evoluiu com sonolência e às 20:00h apresentou uma crise convulsiva, após realizou-se tomografia de crânio. A prescrição do dia foi: dieta leve, SG 5\% $500 \mathrm{~mL}+$ complexo b 8/8 h, uma ampola de plasil, uma de ondansentrona e outra de dipirona por via endovenosa, diazepam $10 \mathrm{mg}$ endovenoso e uma ampola de gardenal intramuscular. Foi ofertado $\mathrm{O}_{2}$ nasal 4 1/min, sonda Folley, controle da diurese e monitorização de sinais vitais.

Após o quadro convulsivo e o rebaixamento do nível de consciência (Glasgow 10), foi solicitado a avalição da neurologia que suspeitou de uma encefalite. Foi iniciado a terapia empírica para tratamento de encefalite, que consiste em combater o patógeno mais prevalente (Herpes vírus), com a utilização de fanciclovir e dexametasona para diminuir o grau de dano inflamatório de uma possível encefalite pós-infecciosa e ceftriaxona para agentes bacterianos. Ademais, foi utilizado Valproato de Sódio para prevenir novas crises convulsivas. Também foi coletado o Líquido Cefalorraquidiano (LCR) em volume de $4 \mathrm{ml}$, ligeiramente turvo, leucócitos $3 / \mathrm{mm}^{3}$, hemácias $853 / \mathrm{mm}^{3}$, glicose $92 \mathrm{mg} / \mathrm{dL}$ e proteínas $30 \mathrm{mg} / \mathrm{dL}$, características que não indicam para um diagnóstico específico, e solicitado testes pra Herpes Vírus (HSV-1), Citomegalovírus, cultura para bactérias, sorologia para HIV e sífilis, além da sorologia para arbovírus.

\section{Evolução:}

A paciente foi acompanhada e constantemente reavaliada, o teste sorológico para detecção de anticorpos contra antígenos da dengue com resultado IgG positivo e os demais testes negativos. A paciente teve melhora gradual dos sintomas, voltando gradativamente as suas atividades básicas de vida com auxílio de fisioterapia. Ela utilizou sonda nasoenteral por 15 dias após alta. Ademais, houve amnésia lacunar do período de início dos sintomas até a alta hospitalar no dia $1^{\circ}$ de abril de 2020.

Na reavaliação com a neurologia no dia 14 de maio de 2020 a paciente estava utilizando: Valproato de sódio $50 \mathrm{mg} / \mathrm{mL}$ suspensão na dose de $5 \mathrm{ml} \mathrm{e} 8$ gotas de Clonazepam à noite. Valsartana 320mg + hidroclorotiazida 12,5 mg e levotiroxina $25 \mathrm{mcg}$ pela manhã e propranolol $40 \mathrm{mg}$ na frequência de duas vezes ao dia.

\section{Exame Físico (14/05/2020):}

- Bom estado geral, lúcida e orientada no tempo e espaço, anictérica, acianótica, afebril e hidratada. Sem alterações cognitivas na anamnese.

- Ausculta cardíaca: Bulhas rítmicas e normofonéticas em 2 tempos sem sopros.

- Ausculta pulmonar: Murmúrios vesiculares distribuídos universalmente sem ruídos adventícios.

- Abdome: Ruídos Hidroaéreos presentes e normodistribuídos, sem dor à palpação superficial e profunda.

\section{Exame Neurológico (14/05/2020):}

- Para determinação da força foi utilizada a classificação de força do Medical Research Council (MRC)

- Membro superior direito: proximal 4, distal 5

- Membro superior esquerdo: proximal 4, distal 5

- Membro inferior direito: proximal 4, distal 5

- Membro inferior esquerdo: proximal 3, distal 4

- Amplitude de movimento preservada. 
- $\quad$ Reflexo vasto medial aumentado.

- Fraqueza proximal.

Figura 1: Evolução da quantidade de plaquetas da paciente, em células $/ \mathrm{mm}^{3}$

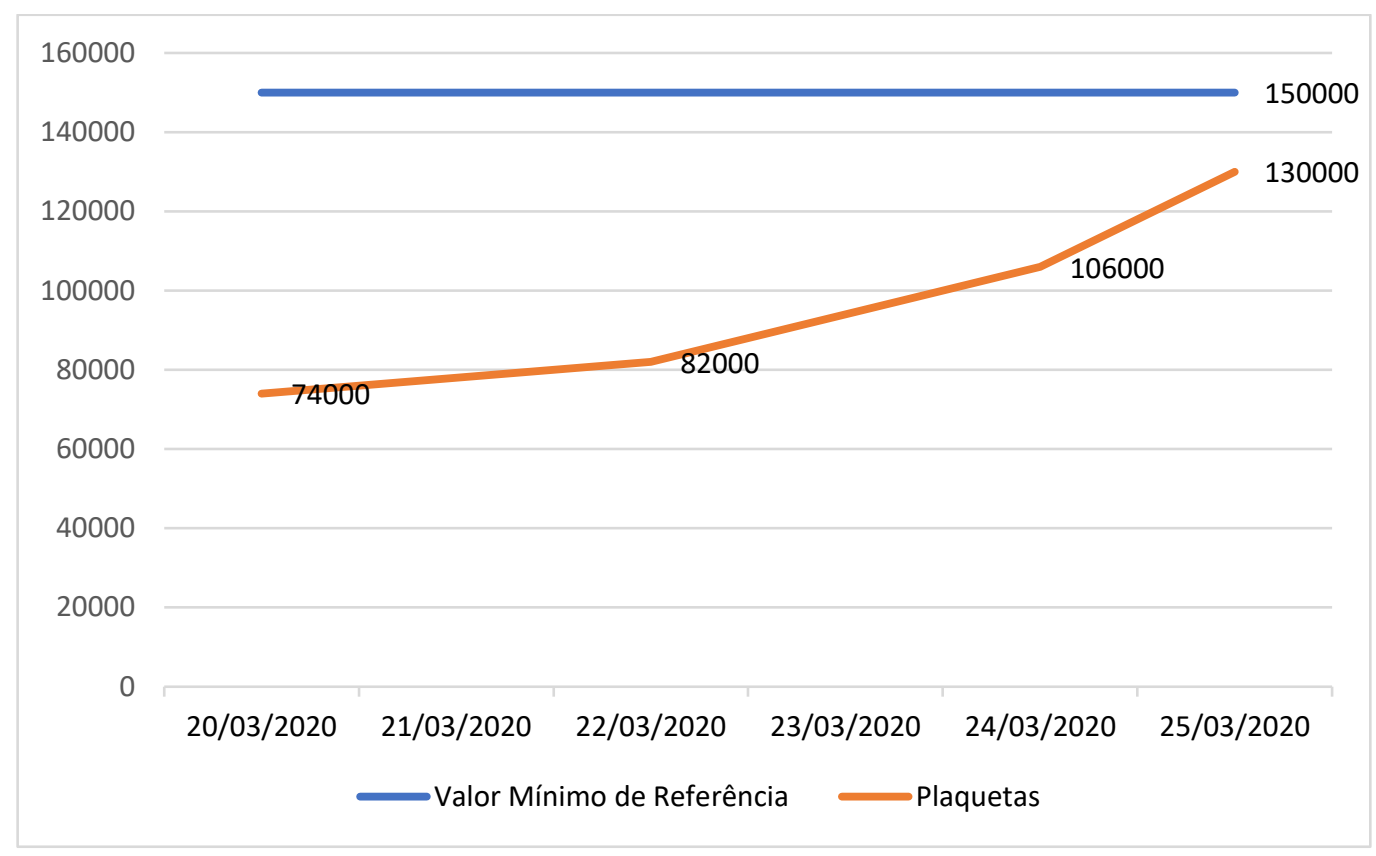

Fonte: Autores (2021)

A trombocitopenia (quantidade de plaquetas $<150 \mathrm{mil} / \mathrm{mm}^{3}$ ) é uma alteração característica em casos de Dengue (Krishnamoorthy et al, 2017; Chao et al, 2019). A paciente apresentou trombocitopenia por todo o período estudado, evoluindo com tendência de aumento na quantidade de plaquetas, chegando próximo ao mínimo fisiológico no dia 25/03/2020 (Figura 1).

Figura 2: Evolução dos valores de transaminase glutâmico-pirúvica (TGP).

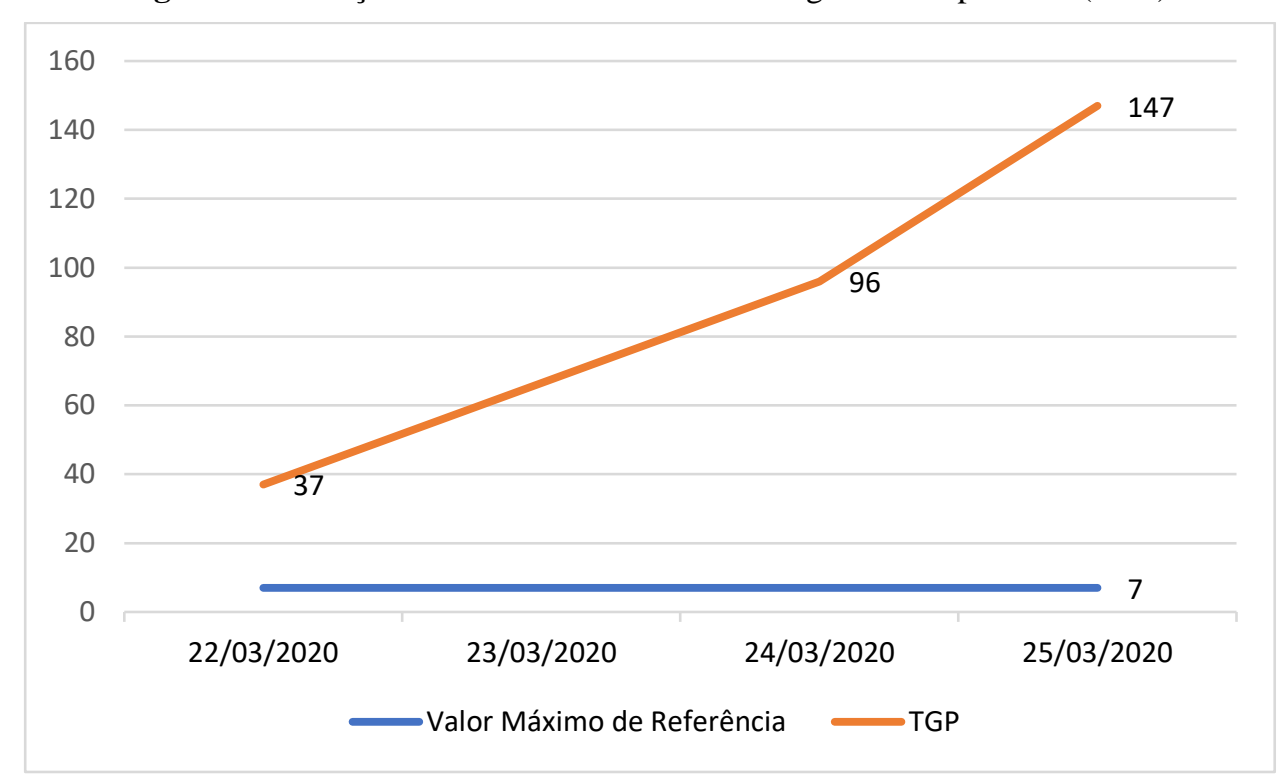

Fonte: Autores (2021) 
Research, Society and Development, v. 10, n. 10, e69101018473, 2021

(CC BY 4.0) | ISSN 2525-3409 | DOI: http://dx.doi.org/10.33448/rsd-v10i10.18473

Figura 3: Evolução dos valores de transaminase glutâmico oxalacética (TGO).

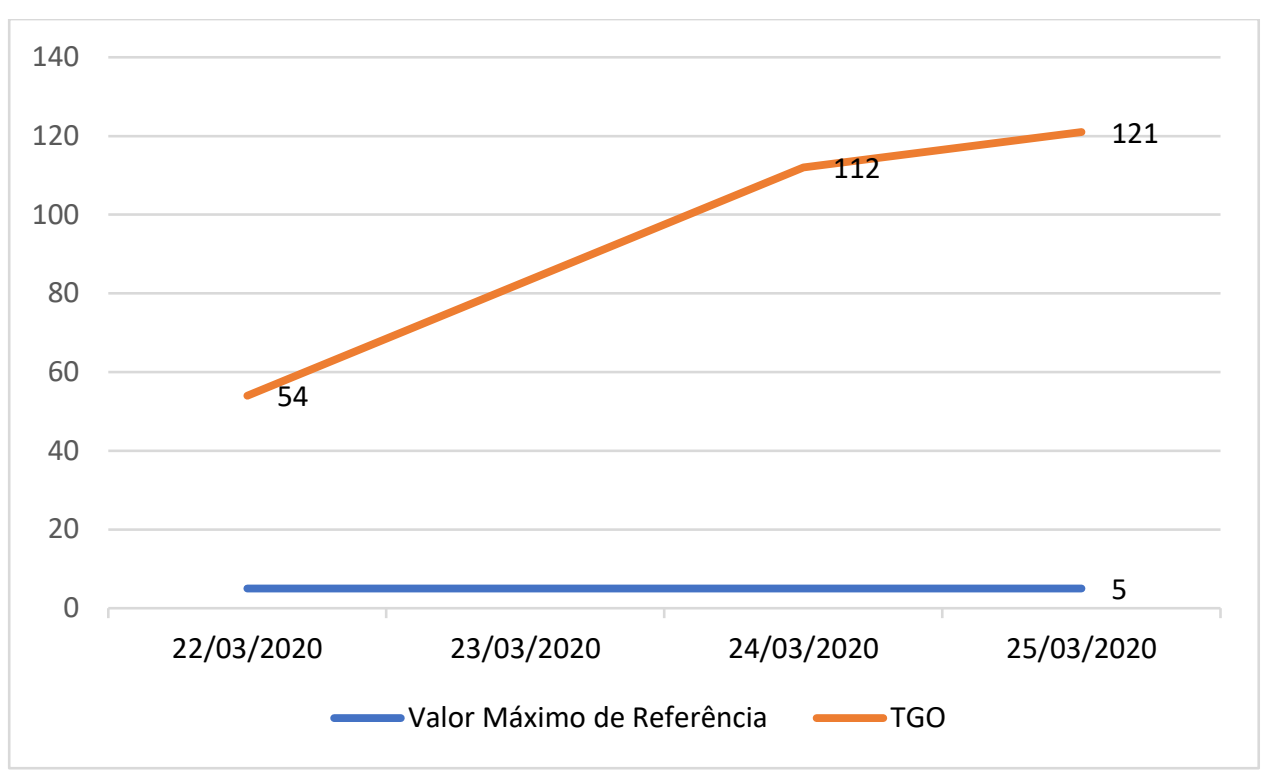

Fonte: Autores (2021)

O aumento dos testes de função hepática (TGO/AST e TGP/ALT) são preditores de severidade na Dengue (Krishnamoorthy et al, 2017). Esses dados estão em conformidade com evolução da paciente, onde houve tendência de aumento de TGO e TGP entre os dias 22/03 e 25/03/2020 (Figura 2 e 3). 
Tabela 1: Evolução dos exames laboratoriais

\begin{tabular}{|c|c|c|c|c|}
\hline Exames & $20 / 03 / 2020$ & $22 / 03 / 2020$ & $24 / 03 / 2020$ & $25 / 03 / 2020$ \\
\hline Eritrócitos & $3.950 .00 / \mathrm{mm}^{3}$ & $4.130 .00 / \mathrm{mm}^{3}$ & $3.770 .00 / \mathrm{mm}^{3}$ & $4.270 .000 / \mathrm{mm}^{3}$ \\
\hline Hemoglobina & $12.2 \mathrm{~g} / \mathrm{dL}$ & $12.5 \mathrm{~g} / \mathrm{dL}$ & $11.6 \mathrm{~g} / \mathrm{dL}$ & $12.9 \mathrm{~g} / \mathrm{dL}$ \\
\hline Linfócitos & $17,30 \%$ & $36,90 \%$ & $26,80 \%$ & $64 \%$ \\
\hline Neutrófilos & $70,40 \%$ & $46,60 \%$ & $63,10 \%$ & $27,40 \%$ \\
\hline Plaquetas & $74000 / \mathrm{mm}^{3}$ & $82000 / \mathrm{mm}^{3}$ & $106000 / \mathrm{mm}^{3}$ & $130000 / \mathrm{mm}^{3}$ \\
\hline Leucócitos & $2000 / \mathrm{mm}^{3}$ & $5000 / \mathrm{mm}^{3}$ & $3800 / \mathrm{mm}^{3}$ & $9300 / \mathrm{mm}^{3}$ \\
\hline TGO & & 54 U.I./L & 112 U.I./L & 121 U.I./L \\
\hline TGP & & 37 U.I./L & 96 U.I./L & 147 U.I./L \\
\hline VCM & $95.2 \mu^{3}$ & $97.3 \mu^{3}$ & $93.1 \mu^{3}$ & $92.4 \mu^{3}$ \\
\hline $\mathrm{HCM}$ & $30.9 \mathrm{pg}$ & $30.3 \mathrm{pg}$ & $30.8 \mathrm{pg}$ & $30.2 \mathrm{pg}$ \\
\hline Creatinina & & & 0,75 & $0.61 \mathrm{mg} / \mathrm{dL}$ \\
\hline Bilirrubina total & & & & $1.94 \mathrm{mg} / \mathrm{dL}$ \\
\hline Bilirrubina direta & & & & $0.81 \mathrm{mg} / \mathrm{dL}$ \\
\hline Bilirrubina & & & & II \\
\hline indireta & & & & $1.15 \mathrm{mg} / \mathrm{dL}$ \\
\hline Ureia & & & & $15 \mathrm{mg} / \mathrm{dL}$ \\
\hline Sódio & & & & $136 \mathrm{mEq} / \mathrm{L}$ \\
\hline Potássio & & & & $4 \mathrm{mEq} / \mathrm{L}$ \\
\hline
\end{tabular}

Fonte: Autores (2021).

\section{Discussão}

Segundo dados oficiais do MS, no ano de 2019 foram notificados 1.544 .987 casos de dengue em território nacional (prevalência de 753,2 casos por 100 mil habitantes), sendo que 1.419 foram casos graves (Ministério da Saúde, 2020). É importante salientar que não houve a descrição dos casos graves.

No mundo é estimado um número total de 100 milhões de infecções e 25.000 óbitos. Existem numerosas manifestações neurológicas como mielite transversa, síndrome de Guillain-Barré e encefalopatia, esta, com incidência de 0,6 a 6,2\% dos casos, será o objeto deste relato.

Suponha-se que alguns mecanismos fisiopatológicos sejam responsáveis pela sintomatologia. A priori é descrito uma forma de encefalopatia por insuficiência hepática, liberação de neurotoxinas, hemorragia intraparenquimatosa por extravasamento e insuficiência na produção de fatores de coagulação. A posteriori um mecanismo de resposta imunológica indireta, pós-infecciosa devido a fatores inflamatórios filtrados nos LCR, ou, ainda não comprovado, infecção direta e encefalite (Borawake et al, 2011).

No caso supracitado podemos sugerir a segunda hipótese, com resposta imunológica indireta devido à evolução. Foi demonstrado um processo gradual de piora sintomatológica e uma melhora dos exames laboratoriais a partir do décimo dia, a plaquetopenia foi reduzida gradualmente como demonstrado na Figura 1. Seguindo a história natural da doença e contrastando com a resposta imune temos um período em que elas sinergizam, de 7 até 14 dias, período em que a resposta imune adaptativa é montada (Abbas, Lichtman \& Pillai, 2015) e a encefalite pós infecciosa ocorre.

Os achados clínicos de encefalite se demonstram muito claros, o sinal de Babinski em membro inferior direito indica distúrbio no córtex frontal esquerdo, com liberação do $2^{\circ}$ neurônio motor, e a flexão do membro superior esquerdo, indica perda 
da inibição do núcleo rubro pelo córtex direito. Estas lesões focais, associadas com o rebaixamento de consciência, náuseas e êmeses são clássicos da encefalite asséptica (Machado \& Haertel, 2013).

Descartados outras causas prováveis, considerar-se-á o diagnóstico laboratorial e clínico de Dengue. Comprovado à posteriori por teste sorológico de detecção de IgG Como profilaxia para encefalite herpética iniciou-se fanciclovir no $21^{\circ}$ dia, respaldado pelo protocolo de encefalite da Sociedade Brasileira de Neurologia (Neto \& Takayanagui, 2013).

\section{Considerações Finais}

O caso descrito acima alerta para manifestações atípicas da Dengue, uma doença altamente prevalente que pode apresentar, mesmo que com baixa incidência, quadros neurológicos de difícil diagnóstico. Lembrar desta manifestação como diagnóstico diferencial é de suma importância em território nacional em consonância com a importância epidemiológica do agente causador.

A paciente teve evolução favorável, com sequelas mínimas, reforçando a necessidade de um diagnóstico rápido associado aos protocolos baseado em evidências que concernem a prática médica. Além disso, o levante hipotético reduz a iatrogenia e procedimentos de alto custo sem importância diagnóstica.

Futuros trabalhos podem abordar a temática da encefalite pós viral ao estudar observacionalmente a proporção de pacientes com quadros de dengue que desenvolvem quadros de encefalite após a resolução do quadro agudo. Além disso, pode ser comparado a frequência de pacientes que desenvolvem encefalite pelo vírus da dengue com outras arboviroses como Zika e Chikungunya.

\section{Referências}

Abbas, A., Lichtman, A., \& Pillai, S. (2015). Imunologia Celular e Molecular (8a ed). Elsevier.

Baheti, G., Mehta, V., Ramchandani, M., \& Ghosh, G. C. (2018). Dengue fever with encephalitis: A rare phenomenon. BMJ Case Reports, 2018, 1-3. https://doi.org/10.1136/bcr-2018-225463

Borawake, K., Wagh, A., \& Dole, S. (2011). Dengue encephalitis. Indian Journal of Critical Care Medicine, 15(3), 190-193. https://doi.org/10.4103/09725229.84896

Chao, C. H., Wu, W. C., Lai, Y. C., Tsai, P. J., Perng, G. C., Lin, Y. S., \& Yeh, T. M. (2019). Dengue virus nonstructural protein 1 activates platelets via Tolllike receptor 4, leading to thrombocytopenia and hemorrhage. PLoS Pathogens, 15(4), 1-26. https://doi.org/10.1371/journal.ppat.1007625

Collao-Parra, J. P., Romero-Urra, C., \& Delgado-Derio, C. (2018). Encefalitis autoinmunes: criterios diagnósticos y pautas terapéuticas. Revista Médica de Chile, 146(3), 351-361. https://doi.org/10.4067/s0034-98872018000300351

Fonseca, M. F. (2016). Segunda opinião formativa: como é realizado o diagnóstico de dengue? https://bit.ly/2VGVt9h

Guzman, M. G., Gubler, D. J., Izquierdo, A., Martinez, E., \& Halstead, S. B. (2016). Dengue infection. Nature Reviews Disease Primers, 2, 1-26. https://doi.org/10.1038/nrdp.2016.55

Homero, V. (2010). Vírus da dengue pode levar a transtornos neurológicos. FAPERJ - Fundação Carlos Chagas Filho de Amparo à Pesquisa Do Estado Do Rio de Janeiro. https://bit.ly/2Bx6umR

Instituto René Rachou. (2020). Dengue. Agência Fiocruz de Notícias. https://bit.ly/2YUVgSc

Kamal, M., Kenawy, M. A., Rady, M. H., Khaled, A. S., \& Samy, A. M. (2018). Mapping the global potential distributions of two arboviral vectors Aedes aegypti and Ae. albopictus under changing climate. PLOS ONE, 13(12), e0210122. https://doi.org/10.1371/journal.pone.0210122

Khetarpal, N., \& Khanna, I. (2016). Dengue Fever: Causes, Complications, and Vaccine Strategies. Journal of Immunology Research, 2016, 1-14. https://doi.org/10.1155/2016/6803098

Krishnamoorthy, S., Bhatt, A. N., Mathew, C. T., \& Ittyachen, A. M. (2017). Hepatitis and thrombocytopenia: markers of dengue mortality. Tropical Doctor, 47(2), 136-141. https://doi.org/10.1177/0049475517691878

Machado, A., \& Haertel, L. M. (2013). Neuroanatomia funcional (3a ed). Atheneu.

Ministério da Saúde. (2020). Boletim Epidemiológico 02: Monitoramento dos casos de arboviroses urbanas transmitidas pelo Aedes (dengue, chikungunya e zika), Semanas Epidemiológicas 1 a 52. 
Research, Society and Development, v. 10, n. 10, e69101018473, 2021

(CC BY 4.0) | ISSN 2525-3409 | DOI: http://dx.doi.org/10.33448/rsd-v10i10.18473

Ministério da Saúde. (2020). Boletim Epidemiológico 21: Monitoramento dos casos de arboviroses urbanas transmitidas pelo Aedes Aegypti (dengue, chikungunya e zika), Semanas Epidemiológicas 1 a 20, 2020.

Neto, J. P. B., \& Takayanagui, O. (2013). Tratado de Neurologia da Academia Brasileira de Neurologia. Elsevier.

Newman, M. P., Blum, S., Wong, R. C. W., Scott, J. G., Prain, K., Wilson, R. J., \& Gillis, D. (2016). Autoimmune encephalitis. Internal Medicine Journal, 46(2), 148-157. https://doi.org/10.1111/imj.12974

Porwal, J., \& Chauhan, A. (2016). Dengue Encephalitis. The Journal of the Association of Physicians of India, 64(8), 99-100. http://www.ncbi.nlm.nih.gov/pubmed/27762126

Varatharaj, A. (2010). Encephalitis in the clinical spectrum of dengue infection. Neurology India, 58(4), 585. https://doi.org/10.4103/0028-3886.68655 Yin, R.K. (2015). O estudo de caso. Porto Alegre: Bookman. 